\title{
Teach-in: the Academic Librarian's Key to Status?
}

\begin{abstract}
One way librarians have of meeting the responsibilities of faculty status is through involvement in the formal instructional programs of their own or other institutions. The author surveyed the population of the academic institutions holding membership in the Association of Research Libraries in the Winter of 1968/69 to determine how many librarians were involved in formal teaching programs. Only 2.75 percent of the total professional FTE staffs do any formal teaching.
\end{abstract}

\begin{abstract}
As
MORE AND MORE INSTITUTIONS award faculty status to the staff librarian, the participation of the librarian in nonlibrary activities assumes new importance. Academic status presumes both privileges and responsibilities. Such responsibilities may include membership on academic committees pertaining to curriculum planning and development, student admissions, faculty selection, and institutional governance. There is the obligation to engage in research, to publish, and to take an active part in the work of professional associations. Another way for the librarian to fulfill his faculty responsibility would be through the mechanism of the formal instructional program of the institution. However, since the professional literature in the field sheds little insight on this problem, an instrument to tap relevant primary source data was developed for this study. The instrument, consisting of ten questions, was administered by mail in the winter of $1968 / 69$
\end{abstract}

Dr. Mary B. Cassata is Assistant Director for Public Services at the State University of New York at Buffalo. to the population of the seventy-one academic institutions holding membership in the Association of Research Libraries. Fifty-seven libraries ( 80.3 percent) responded to the questionnaire, three refused to respond, and eleven libraries failed to respond. However, of the responses received, one questionnaire was lost and another was received after the questionnaires had been analyzed and the tabulations completed, thus reducing the number of usable responses to 55 , and thus yielding a final response of 77.5 percent.

The letter which accompanied the first mailing of the questionnaires stated the purpose of the study and stressed the importance of the respondent's using care and accuracy in the answering of the questions. Almost all of the questions had been deliberately designed to be open-ended, with the exception of one which required a "yes" or "no" response. "The validity of the study," the letter stated, "depends upon the consistency of definitional meanings, which can only become apparent in the explanations given in the answers to the questionnaire." A follow-up letter, which 
also repeated the same precautionary message, was mailed approximately one month later to those libraries which had failed to respond to the initial mailing. The libraries participating in the study were all promised copies of the analysis of the responses to the questionnaire.

The first three questions attempted to develop the contextual framework for the study, i.e., to obtain data on the participation of librarians in the formal instructional programs of their institutions. The first question, for example, probed the matter of academic appointments of the library staff; question two examined the topic of title and rank; and question three dealt with the similarities or differences in the criteria for the appointment, promotion, and tenure of the librarian as compared with the faculty.

Question four, a two-part question, attempted to come to grips with the essence of the problem, asking whether the library's professional staff did in fact participate in the formal teaching program of the parent or other institutions. The next four questions, which were to be answered by only those libraries whose professional staff participated in the institution's formal teaching program, solicited information on the type of appointment held, the courses being taught, the method of compensation for the librarian, and the compensation, if any, for the library. The final two questions, which were to be answered by all the respondents, dealt with the librarian's involvement in less formalized instructional programs, such as conducting orientation lectures and tours, delivering lectures on specialized bibliography upon request, and training library interns.

\section{Data Analysis}

The explication of the first question by the respondent was essential to avoid the generally loose interpretations of the term, "academic appointment." When

this question was analyzed, it seemed apparent that in most cases deliberate care had been exercised by the respondent to distinguish between the concepts of "academic status," "faculty status," and "professional appointments." (See Table 1.)

TABLE 1

Status of Librarians

Question 1: Do the members of your professional staff have academic appointments? Explain.

$$
\text { Response }
$$

Academic Status

Faculty Status

Professional Appointment

Faculty Status, if teaching; otherwise professional appointment

Administrators, faculty status; others, academic status

Such responses as "All librarians on this staff have faculty status and full faculty rank," or "Librarians having a master's degree from an accredited library school and no experience are appointed to the rank of instructor; department heads with second master's degrees or equivalent in subject fields or long experience are given faculty status and are appointed to the rank of Assistant Professor" were coded as meaning "Faculty Status." The response "Academic, yes; faculty, no" was coded as meaning "Academic Status"; and "They are considered professionals but not faculty" was placed in the category, "Professional Appointment." Apparently, this question would have been stronger if it had not been open-ended; some ambiguity may have been eliminated if the categories "Academic Status," "Faculty Status," and "Professional Appointment," together with their accepted definitional meanings, had been supplied.

The second question (see Table 2), dealing with the problem of title and rank, revealed that nearly half of the librarians held both librarian title and librarian rank, while less than one-third held librarian titles and professorial rank. 
TABLE 2

Title and RaNK of Librarians

Question 2: Does your professional staff have librarian title and rank? Or, professorial title and professorial rank?

Response

Librarian title, with Librarian rank Librarian title, with professorial rank Title and Rank Dependent upon Appointment

Professorial title, with Professorial rank Librarian title, with no specified rank No response

Percentage

45.5

30.9

At one institution where the librarians held professorial title and professorial rank, that respondent stated flatly, "It has been difficult to secure promotion in rank from the University Promotion and Tenure Committee because the membership of this committee in some instances have not thought librarians to perform academic type functions. One member of the committee expressed it this way: 'Librarians perform services for academic personnel. They are not academicians!' " Therefore, while it may appear that, as a class, librarians are making gains in the province generally considered sacrosanct by the faculty, the bias of the faculty toward librarians remains.

The responses to the third question, interpreted within the framework of the responses made to the previous two questions, appeared to support the assumption of the questionnaire's internal consistency. Question three asked whether the criteria for the appointment, promotion, and tenure of the professional staff of the library were the same as the criteria for the appointment, promotion, and tenure of the faculty. The responses $(\mathrm{N}=55)$ showed that in 47.3 percent of the libraries sampled, the criteria were different; in 27.3 percent, the criteria were the same; and in $\mathbf{1 4 . 5}$ percent of the libraries, the criteria were similar. One respondent professed not to know the criteria for the faculty, and 9.1 percent of the respondents ignored the question alto- gether. One library, claiming the criteria for the appointment, promotion, and tenure of librarians to be the same as for faculty, responded, "A dossier is prepared containing such information as the personal history of the candidate, academic degrees, appointments, research and publications, consultation opportunities, membership in professional organizations, and community service." On the other hand a respondent claiming the criteria to be similar but not identical, pointed out that there were the "same formal requirements of service, personal characteristics, research, and publication, but that instead of teaching ability and scholarship, [the librarian is required to show] professional ability as evidenced by vigorous pursuit of library problems and the promotion of their solutions; effective administrative performance in the area of responsibility; and creative development in the position."

The first part of the fourth question required a "yes" or "no" response relative to the involvement of the library staff in the institution's formal teaching program. Although 61.8 percent of the libraries responded that members of their staffs were involved in the formal instructional programs of their institutions (another 16.4 percent stated that involvement was "intermittent" or "only occasional"), this response should be viewed with some caution. Admittedly, while there are some members of the staff who engage in teaching, this should not be interpreted as meaning that a large segment of any library staff teaches. There was no involvement at all in teaching according to 21.8 percent of the sample.

As for involvement in the teaching programs of outside institutions (question $4 \mathrm{~b}$, Table 3 ), again the responses should be interpreted cautiously. While at first glance the response reveals that the librarians of more than one-third of the institutions engage in outside teach- 
ing activity, careful examination of the data shows that the teaching is done during sabbaticals or summer vacations, or at nearby institutions (or only "upon occasion").

TABLE 3

Teaching in OUtside Institutions

\begin{tabular}{lc} 
Question $4 \mathrm{~b}: \begin{array}{l}\text { Do the professional members of the } \\
\text { library staff participate in the teaching } \\
\text { programs of outside institutions? }\end{array}$ \\
\hline Response & Percentage \\
Yes & 34.6 \\
No & 56.3 \\
No response & 9.1 \\
\hline
\end{tabular}

The question of joint appointments was the rationale for including question five (see Table 4). In one of the libraries

TABLE 4

JoInt AppoINTMENTs

Question 5: Do the library staff members who also have teaching assignments in academic departments hold joint appointments?

Response

Hold joint appointments

Do not hold joint appointments

Not applicable

Percentage

56.4

20.0

23.6

where the teacher-librarian did not hold joint appointments it was noted that the courses taught were "library-related" and were "part of the duties of the librarian concerned." In another library which also disclaimed "joint" appointments, each staff member arrived at his own "arrangement"-in terms of salary, rank, and courses taught-with the academic department concerned. A large midwestern institution reported that "the teacher-librarian works four hours daily in Reference and teaches two courses in Library Science, with one-half salary paid by the library and one-half by the academic department." It should be emphasized, however, that upon careful examination of the data, it became apparent that such situations applied to only a few librarians in each institution, or that the joint appointment was of a temporary nature, or that it applied to the library director alone. It is also interesting to note that the librarian singled out the most frequently as holding a joint appointment seemed to be the Law Librarian.

The method of compensating those teaching librarians who did not hold joint appointments was also investigated.

TABLE 5

Compensation to THE LibraRians FOR Teaching

Question 6: If joint appointments are not held by the library staff who also teach, how are these individuals compensated for their teaching?

Response

Percentage

Librarian paid additionally 21.8

Librarian given preparation time

Library compensated for extra help 9.1

No compensation, no time off $\quad 7.3$

No response or question not applicable 41.8

There appeared to be considerable maneuverability with regard to compensation for extra teaching responsibilities, in the absence of a joint appointment. In some instances, for example, the teaching librarian was rewarded by the library with time off for course preparation; in other cases, the librarian was paid additionally, or student help was given to offset the librarian's time spent away from his department, or, again, the individual was given neither compensation nor time off for preparation.

The counterpart to the question on compensation to the librarian was the question of compensation to the library. Little additional insight was gained from the data other than to learn that in 38 percent of the cases, the library was not compensated and that in 54 percent of the cases, the question was either not relevant or not answered.

One respondent stated, "The library is not compensated in any financial way when its staff members teach courses for academic departments. Nor are we given any additional staff to make up for time lost. However, we feel our compensation comes in the form of greater 
acceptance of library staff members by the rest of the faculty." Another respondent stated: "If a joint appointment is made, then there is a salary adjustment. Otherwise, the library is not compensated financially but hopefully reaps the benefit of 'good will." "

The respondents were asked in question eight to identify their librarians teaching at the time of this survey, by the title of their library position, the rank held, if any, in the relevant academic department, and the courses taught. This question yielded some of the most interesting information in this survey. When the data was tabulated, it was found that 123 librarians, 112 of whom held faculty rank, were teaching 138 courses in 28 academic departments. On the basis of the ARL Academic Library Statistics, 1967-1968, the fifty-five libraries participating in the study had a total professional staff of 4,473 FTEs. On the basis of this figure (which is probably understated), only 2.75 percent of the professional staff is involved in teaching. It was also apparent that 70 percent of the librarians, engaged in teaching, held the rank of department head or some higher administrative post. Of the 30 percent remaining-i.e., those representing the bread-and-butter librarian-86 percent were subject bibliographers. With the greater proportion of teacher-librarians coming from the upper administrative level, it was not an unexpected finding that 52 percent of the total population of the teaching staff should hold academic titles of Professor or Associate Professor. The remaining 48 percent was almost equally assigned to the Assistant Professor or the Lecturer/Instructor ranks.

Predictably 93 of the 138 courses taught by the academic librarian were in the subject field of librarianship. In addition to such traditional library courses as book selection, cataloging, and reference, these subjects included library administration, archives and manuscript management, government documents, information science, and media instruction, all taught for the Department or School of Library Science. There were also courses in the subject bibliography of such disciplines as chemistry, Chinese, engineering, history, Islamic studies, Japanese, music, medicine, and nuclear engineering, taught within the appropriate academic departments. Courses in such subject areas as architecture, botany, business, education, English literature, journalism, law, research methodology, social work, and sociology completed the librarians' repertoire.

The last two questions (see Tables 6 and 7 ), recognizing that the greater part of the "teaching" function of librarians is generally done informally in the library setting, attempted to examine the degree to which such programs as library orientation tours and library intern programs are structured. In both questions, the respondent was encouraged to supply as many options as applied to his library.

TABLE 6

Informal Instructional Programs OF LIBRARIES

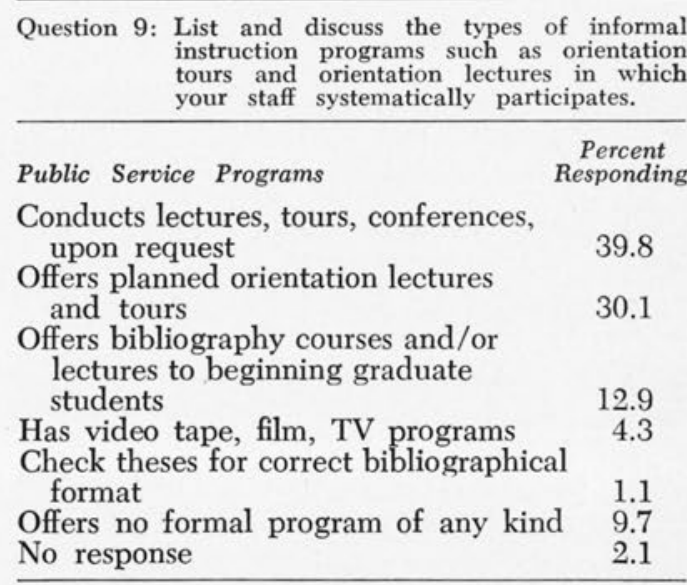

\section{Summary}

This study was undertaken to examine the participation of the academic librarian in the formal instructional pro- 
TABLE 7

LIBRARY/INSTITUTIONAL COOPERATION

Question 10: Does your library cooperate with your institution's academic departments by employing or training library interns, graduate assistants, etc.?

\begin{tabular}{lc}
\hline Response & Percentage \\
Yes & 64.6 \\
No & 30.8 \\
No response & 4.6 \\
\hline
\end{tabular}

gram of his institution. It confirmed the general finding in the literature that the status of the librarian is at best ambiguous. Of the fifty-five ARL libraries participating in this survey, less than 31 percent claimed faculty status for professional staff, and 45 percent claimed that their staffs held librarian title and librarian rank. In nearly two-thirds of the libraries surveyed, the criteria for the appointment, promotion, and tenure of the librarian differed from the criteria for the faculty. Although 60 percent of the libraries reported that some members of their staffs were involved in the formal instructional programs of their institutions, this meant less than 2.75 percent of the total professional FTE staffs of these libraries were involved in teaching. There appeared to be little consistency among these libraries with regard to joint appointments and the method of compensation to the librarian. 